Article

\title{
Evaluation of Masticatory Muscle Function Using Digital versus Traditional Techniques for Mockup Fabrication: A Controlled Prospective Study
}

\author{
Simona Tecco ${ }^{\mathbb{D}}$, Francesca Cattoni ${ }^{\dagger}$, Atanaz Darvizeh, Floriana Bosco, Vincenzo Sanci, \\ Alessandro Nota $*+\mathbb{D}$, Giorgio Gastaldi and Enrico Felice Gherlone \\ Dental School, Vita-Salute San Raffaele University and IRCCS San Raffaele Hospital, 20132 Milan, Italy; \\ tecco.simona@hsr.it (S.T.); cattonif@tiscali.it (F.C.); atanazdarvizeh@gmail.com (A.D.); \\ boscofloriana@gmail.com (F.B.); sancivincenzo@libero.it (V.S.); gastaldi.giorgio@hsr.it (G.G.); \\ gherlone.enrico@hsr.it (E.F.G.) \\ * Correspondence: nota.alessandro@hsr.it \\ † These authors have equal contribution.
}

Received: 10 July 2020; Accepted: 28 August 2020; Published: 31 August 2020

\begin{abstract}
Background: the aim of this longitudinal prospective study was to analyze the effect of digital and traditional mockup on masticatory muscle activity in patients with teeth wear, rehabilitated with an increase of occlusal vertical dimension. Subjects and Methods: a sample of 22 adult patients who were about to receive a prosthetic rehabilitation was divided into a study group (3M; $9 \mathrm{~F}$; mean age $42 \pm 0.8$ years), treated using the digital mockup; and a control group ( $2 \mathrm{M}$; $8 \mathrm{~F}$; mean age $37 \pm 0.5$ years), treated using the conventional technique (traditional) mockup. Electromyographic activity of anterior temporalis and masseter muscles were evaluated before the beginning of the treatment (T0), at mockup insertion (T1), after treatment (T2) and each lapse of time lasted 2-5 months. Results: the comparison between the two groups at different time gaps revealed that at $\Delta 1$ (T1-T0) only the impact index (IMP) showed significant difference and no other significant variation was observed between the two groups at $\Delta 2$ (T2-T1) and $\Delta 3$ (T2-T0). It concludes that traditional and digital methods generally have nonsignificant differences. Conclusions: both methods seem to be effective in prosthetic rehabilitation and give comparable effects on masticatory muscles.
\end{abstract}

Keywords: intraoral scanners; digital dentistry; CAD/CAM mockup; aesthetic crown; masticatory muscles; surface electromyography; masseter muscle; temporal muscle; dental occlusion; gnathology

\section{Introduction}

Prosthetic rehabilitation for the treatment of tooth wear has become increasingly diffused over the last two decades [1], since new approaches have emerged to reconstruct worn teeth in a minimally invasive way [2,3]. The new procedures include a wax and a mockup that are primarily used to design and previsualize both aesthetic and functional outcomes. The mockup is often limited to the treatment of anterior areas, mainly to test aesthetics and phonetics [1].

However, in cases of extensive rehabilitation, it is also used on posterior teeth, to manage a reversible and effective procedure, and evaluate and test functional aspects [2,4]. In some cases, mockup is an important step to achieve a new occlusal vertical dimension (OVD), and a guide for the preparation of anterior and posterior teeth. Thus, it represents a mandatory step in the entire procedure. Especially when the treatment requires OVD reconstruction. A recent systematic review pointed that there are many methods to detect the OVD, depending on clinical judgment and clinical preferences (in particular, facial aesthetics and mandible physiological rest position). It could be concluded from 
the Alhaji et al. study that, in general, all the available techniques have merits and are helpful for routine clinical use [5].

Recently, a computer-aided manufacturing method, which simplifies the preparation of both mockup and final prosthesis, was introduced. This digital technique provides the adequate design for mockup from the initial scan [6]. With this digital approach, data concerning fracture, sensitive teeth, pain, gingival recession, deboning, chipping, micro leakage, discoloration, secondary caries and root canal therapy were evaluated with satisfactory clinical results [6,7].

However, literature lacks data about the function of masticatory muscles in these subjects after rehabilitation. Thus, the aim of the present study is to analyze the effect of digitally designed and CAD/CAM milled mockups and traditional mockups on masticatory muscle activity in patients with teeth wear [8,9], rehabilitated with an increase of OVD. The null hypothesis is that there is no difference between the effects of the two techniques on masticatory muscle activity.

\section{Materials and Methods}

This study was carried out at the Department of Dentistry of San Raffaele University, Milan, in the period between July 2016 and December 2018. During that period, 22 patients ( 5 males and 17 females; age range: $24-65$ ) were scheduled to receive a prosthetic treatment and were enrolled in the present study.

The protocol was approved by the Ethics Committee of the University Vita-Salute San Raffaele (Approval code 9/INT/2015). All the methods were carried out in accordance with relevant guidelines and regulations.

The following inclusion criteria were adopted to select the subjects: adult subjects, absence of temporomandibular disorders (TMD) signs and symptoms, loss of occlusal vertical dimension (OVD) due to teeth wear with exposed dentine [10]. Exclusion criteria were: chronic periodontal pathology, systemic diseases, neurological disorders, and previous prosthetic rehabilitation.

The subjects were informed about the nature of the investigation and an informed consent form was signed prior to participation. They were treated by a dentist with more than 15 years of experience in the field of aesthetic prosthesis (the author F.C.) and the proper OVD was determined by an operator with more than 20 years of experience in temporomandibular function on the base of functional principles of mandibular movement [5].

\subsection{Procedure}

Firstly, a surface electromyography (sEMG) of the anterior temporal and masseter muscles was performed by using the occlusal contact analyzer software called Teethan (BTS S.p.A., Garbagnate Milanese, Milan, Italy) (Figure 1), which consists of 4 wireless probes and an acquisition frequency of $1 \mathrm{kHz}$. This recording was set as T0 data. Then, the subjects were assigned to two different groups: the study group (a) (12 subjects: 3 males 9 females, mean age $42.17 \pm 7$ years) was treated using a computer-aided designed and CAD/CAM milled (digital) mockup and a control group (b) (10 subjects: 2 males, 8 females; mean age $42.2 \pm 10.5$ years) treated using a conventional technique (traditional) mockup. 

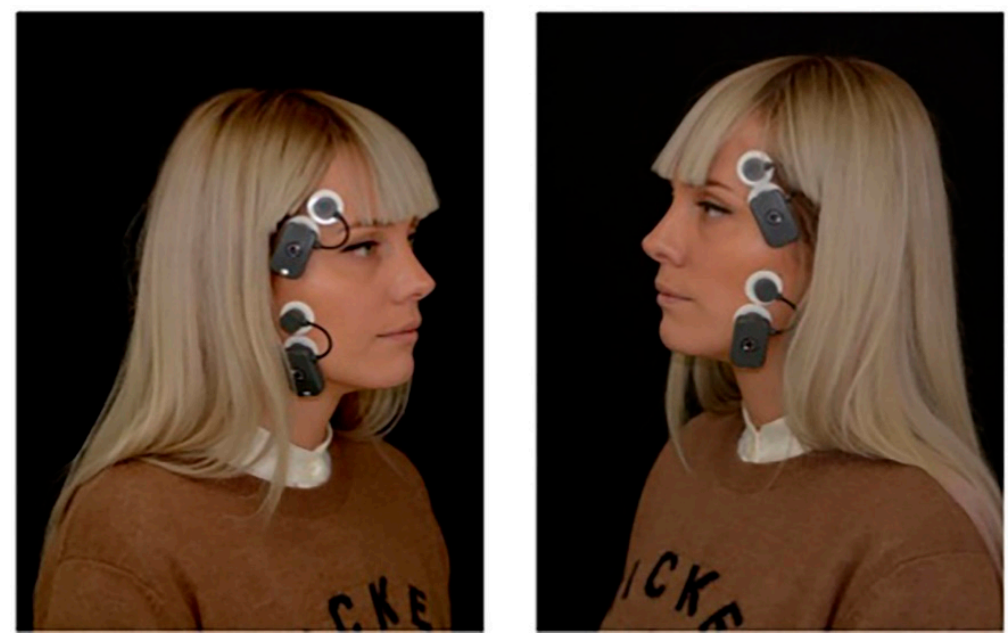

Figure 1. Image of a surface electromyographic exam (Teethan, BTS S.p.A., Garbagnate Milanese, Milan, Italy).

(a) Computer-aided designed/manufactured mockup (digital mockup)

An intraoral scanner (Intra-oral scanner 3D Progress, M.H.T. s.r.l, Verona, Italy) was used to get intraoral digital impressions of the maxillary and mandibular arches while the mouth was open and in static occlusion.

Intraoral scans in .stl format were used to design the mockup using Zirkonzahn.software with virtual articulator (Zirkonzahn s.r.l., Gais, Bolzano, Italy) and milled in PMMA (Bredent s.r.l., Bolzano, Italy), using a milling unit (M1 wet, Zirkonzahn s.r.l., Gais, Bolzano, Italy) (Figures 2 and 3).
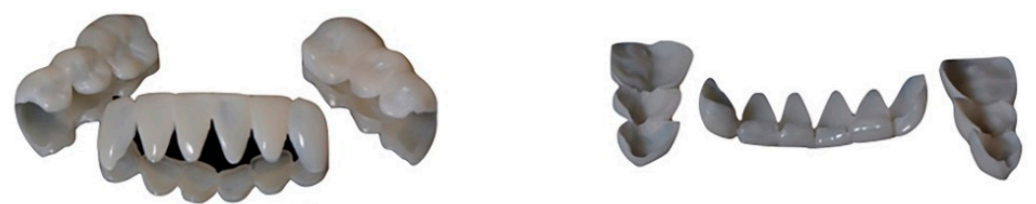

Figure 2. Occlusal, labial/facial and lingual views of the mockup obtained with a digital technique.
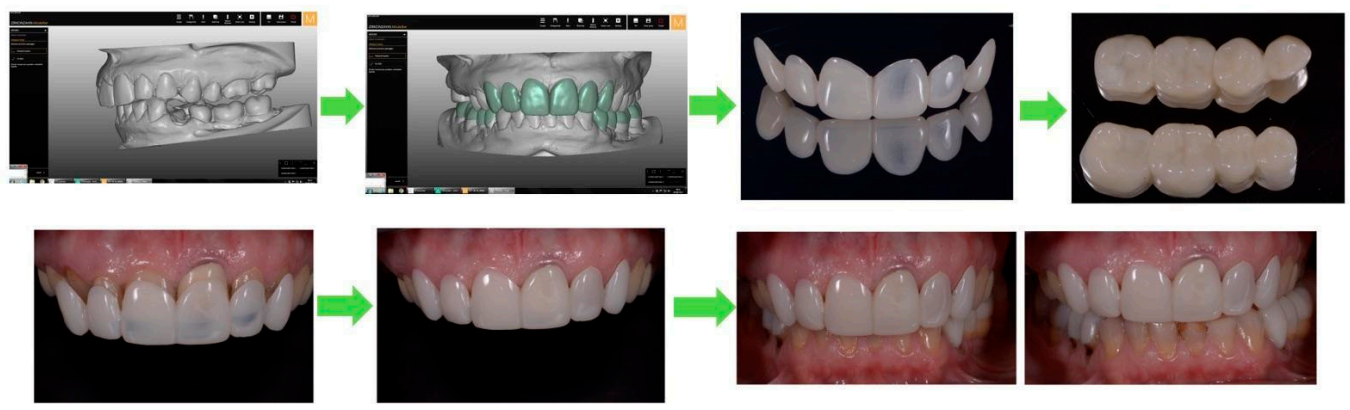

Figure 3. The images represent all the stages of the creation of the digital mockup, from design to insertion in the mouth.

Then, the milled mockup was positioned in the patient's mouth, and at this time another sEMG recording was taken to detect the electrical potentials of the masticatory muscles (this recording was considered in T1).

Figure 2 represents all the stages of the digital mockup preparation.

In cases where the mockup was not perfectly stable the sEMG data did not document an adequate occlusal symmetry index; so, a touch-up was performed on the same mockup, to improve its stability. Then, a new sEMG recording was accomplished (T1b). Once the desired result was obtained, the definitive mockup was used as the temporary prosthesis. 
(b) Conventional technique (traditional mockup)

Initially, alginate impressions of both upper and lower arches were taken. The overjet and the overbite were then evaluated, and phonetic tests were performed to establish the right length of the central and lateral upper incisors, on which the composite-up (made with Ivoclar Vivadent composite) were bonded to establish the necessary elongations of the clinical crown. Then, a wax was modelled to register the OVD after the composite-up had been placed. This wax represents the OVD to be replicated during the prosthetic rehabilitation procedure. To model the wax, the patient was asked to slowly open the mouth starting from his/her habitual occlusion, freely following his/her usual opening/closing path. The patient was asked to repeat this habitual movement for at least 2-3 times, without placing any wax inside the mouth. Then, in order to register the wax bite, it was anchored on the upper arch (leaving the edge of the upper incisors, reconstructed with composite-up, visible to the patient through a frontal mirror), and the patient was asked to close his/her mouth slowly, respecting his/her usual path without reaching the end of the run, but letting the clinician to establish the stop-point. The clinician established the stop-point of the closing path, with respect to the overjet and overbite values and functional movements of the mandible.

For the wax bite, a red wax sheet (Tenatex, Kemdent, Swindon Wiltshire, United Kingdom) was used, rebased with Aluwax (Aluwax Dental Products Co., Allendale, Michigan, USA), folded several (2-3) times based on the patient's need, until the alleged OVD was obtained (Figure 4).

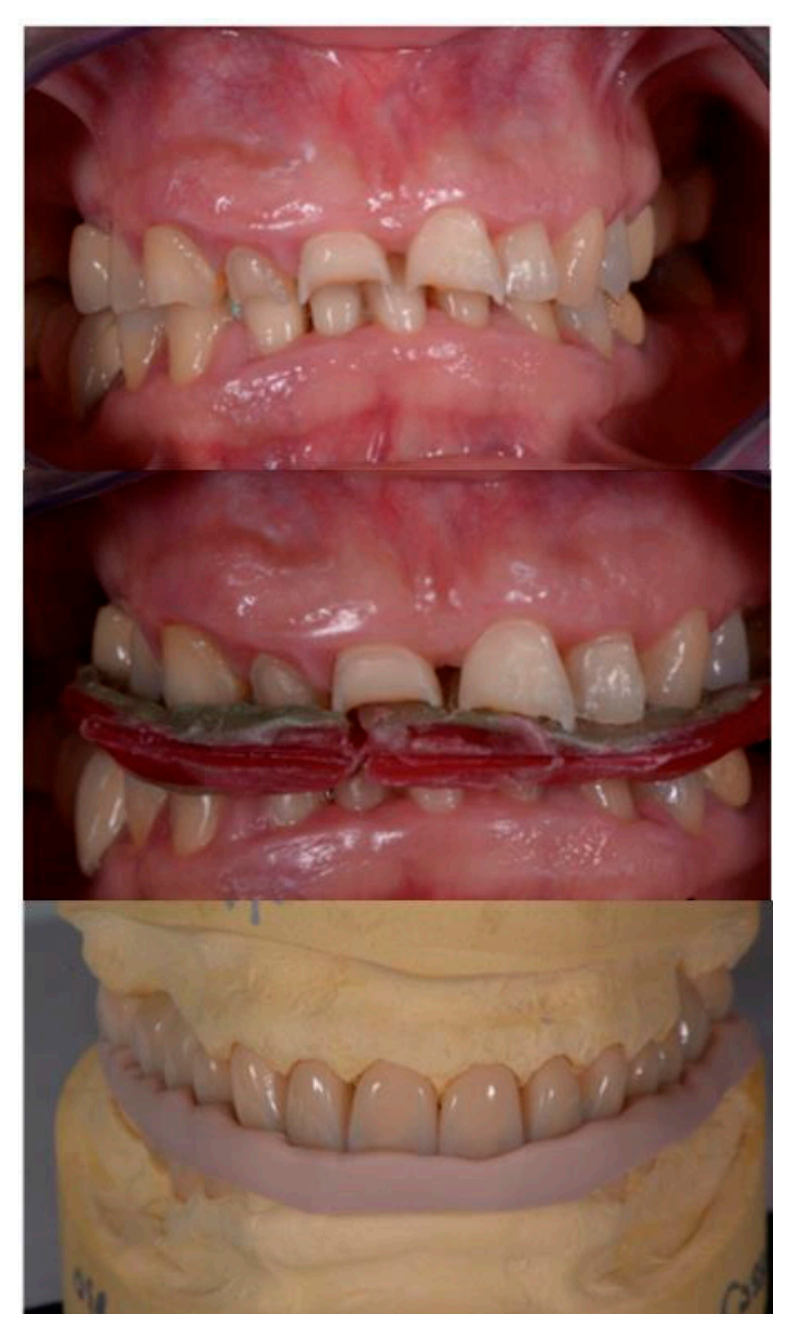

Figure 4. Traditional mockup and wax. 
Then, the wax bite and the alginate impressions were sent to the technician, so a master model in plaster was created and mounted on an average value articulator, considering the relationship provided by the wax registrations. The technician made a rigid resin mockup, which was subsequently tested in the patient's mouth (Figure 4). In this case, an sEMG acquisition was performed with the mockup in the mouth (T1), and, if there were asymmetries, the mockup was functionalized so as to have the occlusal balance of the patient, and the sEMG was repeated (T1b).

\subsection{Temporary and Definitive Prosthesis}

From the acquired information, the technician made the patient's temporary prosthesis. For both groups, the temporary prosthesis was held by the patient for a period of 3-4 weeks. Then, a new intraoral scan was acquired for the realization of the definitive prosthesis, which is made from Zirconia [11].

The definitive prosthesis was designed with an occlusal scheme of unilateral balanced occlusion or mutually protected occlusion according to each single case condition and positioned inside the patient's mouth and after confirming proper stability and contacts, the final prosthesis was cemented. The criteria used for the clinical evaluation were the occlusal stability of the rehabilitation that required stable contacts on all teeth and equal occlusal loads in static occlusion with absence of premature contacts, posterior teeth disclusion during mandibular protrusive movement and correct guidance during mandibular lateral movement with the absence of dynamic premature contacts.

Then, the surface electromyography and the occlusal analyses were repeated, and the desired results were the presence of homogeneous and point contacts between the two dental arches.

Subsequently, a new sEMG test was performed (this point was considered the T2) to evaluate whether there were any variations in the transition from the beginning.

\subsection{Surface Electromyography}

Surface electromyography recordings were taken by the same operator from masseter and anterior temporal muscles, with a wireless medical device able to detect the electrical activity of masticatory muscles, and report some occlusal parameters representing the distribution of loadings on dental arches. During the sEMG examination, the patient was seated in the usual position on a dental chair, where the angle between the chair backrest and the sit was a little more than $90^{\circ}[12,13]$. The patient was asked to maintain a "natural head position" to avoid the undesired head inclinations. This position was obtained in this study by asking the subjects to look straight ahead at a small mirror adjusted at eye level, as described in previous literature [14,15]. The subjects were asked to make themselves comfortable, to relax their arms by their sides, and to look straight without any further head or body movements during the test. With this arrangement, unintentional movements from other parts of the body were eliminated or reduced.

The lapse of time among $\mathrm{T} 0$ and $\mathrm{T} 1$, or $\mathrm{T} 1$ and $\mathrm{T} 2$ varied among the subjects, with a range between 2 and 5 months for completing the rehabilitation. The exam consists of two measurements of muscle activity in maximum intercuspation: the first one, carried out by placing two cotton rolls between the upper and lower teeth, for calibration; the second one, carried out in natural intercuspation, allows the operator to detect the occlusal parameters. Then, the software combines the two tests. Each task lasts $5 \mathrm{~s}$ and at the end of the entire exam (two tasks) the software generates a report of the recorded values, providing a graphical summary. The indices of the report are described in Table 1 [16]. While individual data about treatment group, gender, age and total $\mathrm{T} 0-\mathrm{T} 2$ time lapse are reported in Appendix A (Table A1).

The indices include: POC TA (percentage overlapping coefficient, anterior temporalis muscles), POC MM (percentage overlapping coefficient, masseter muscles), BAR (percentage overlapping coefficient between posterior and anterior teeth contact), TORS (torsion index), IMP (impact index), ASIM (asymmetry index), TOT (total muscular work). Several studies have shown their repeatability and reliability [16-23]. 
Table 1. Variables considered.

\begin{tabular}{|c|c|c|c|}
\hline Variable & Name & Significance & Normal Value \\
\hline POC TA & $\begin{array}{l}\text { Percentage overlapping } \\
\text { coefficient (anterior temporalis } \\
\text { muscles) }\end{array}$ & $\begin{array}{l}\text { A measure of the predominance of } \\
\text { the right or left anterior temporalis } \\
\text { in the anterior teeth contacts }\end{array}$ & $83 \% \leq X \leq 100 \%$ \\
\hline POC MM & $\begin{array}{l}\text { Percentage overlapping } \\
\text { coefficient (masseter muscles) }\end{array}$ & $\begin{array}{l}\text { A measure of the predominance of } \\
\text { the right or left masseter in the } \\
\text { posterior teeth contacts }\end{array}$ & $83 \% \leq X \leq 100 \%$ \\
\hline BAR & $\begin{array}{l}\text { Percentage overlapping } \\
\text { coefficient between posterior } \\
\text { and anterior teeth contact }\end{array}$ & $\begin{array}{l}\text { A measure of the predominance of } \\
\text { the posterior or anterior teeth } \\
\text { contacts }\end{array}$ & $90 \% \leq X \leq 100 \%$ \\
\hline TORS & $\begin{array}{l}\text { Torsion index: percentage of } \\
\text { torsion of the mandible }\end{array}$ & $\begin{array}{l}\text { It is obtained by comparing the } \\
\text { torque of the crossed muscle pairs: } \\
\text { comparison between the torque of } \\
\text { the right temporal and left masseter } \\
\text { pair (for convention torque to the } \\
\text { right) with the torque of the left } \\
\text { temporal and right masseter pair } \\
\text { (for convention torque to the left). }\end{array}$ & $90 \% \leq X \leq 100 \%$ \\
\hline IMP & $\begin{array}{l}\text { Impact index: work performed } \\
\text { by the muscle during its } \\
\text { contractile activity. }\end{array}$ & $\begin{array}{l}\text { The work is represented } \\
\text { geometrically by the area subtended } \\
\text { to the curve of electrical activity of } \\
\text { the muscles examined over time. }\end{array}$ & $85 \% \leq X \leq 115 \%$ \\
\hline ASIM & $\begin{array}{l}\text { Asymmetry index: distribution } \\
\text { of the occlusal contacts } \\
\text { considering the right and left } \\
\text { parts of dental arches, on the } \\
\text { frontal plane. The pairs of } \\
\text { muscles examined are } \\
\text { represented by the temporal and } \\
\text { masseter muscles }\end{array}$ & $\begin{array}{l}\text { It evaluates the distribution of the } \\
\text { occlusal contacts on the two arches, } \\
\text { right and left, and the activities } \\
\text { performed by the temporal and } \\
\text { masseter muscles during clenching. }\end{array}$ & $-10 \% \leq X \leq+10 \%$ \\
\hline TOT & Total muscular work & $\begin{array}{l}\text { Muscular work globally produced } \\
\text { by the four analyzed muscles }\end{array}$ & \\
\hline
\end{tabular}

\subsection{Statistical Analysis}

A statistical analysis was performed using the Statistical Package for Social Sciences (version 23 SPSS Inc., Chicago, IL, USA). All variables were reported as mean \pm standard deviation (SD). To study the changes of each variable at different times and also to compare the variable alterations between two independent groups (traditional and CAD), the Wilcoxon Signed Ranks Test and Mann-Whitney U Test were used. The level of statistical significance was 0.05 .

\section{Results}

A total number of 22 patients completed the study, among them ten patients (mean age $37 \pm 0.5$ years) were treated by using the traditional technique while twelve patients (mean age $42 \pm 0.8$ years) underwent digital treatment. In general, in the whole sample it registered an increase of OVD of about $1.5-3.5 \mathrm{~mm}$.

For each group seven parameters were assessed by means of electromyography at pretreatment (T0), midtreatment (T1) and post-treatment (T2) times.

Tables 2 and 3 show the mean \pm SD values of each variable at different times $(\mathrm{T} 0, \mathrm{~T} 1, \mathrm{~T} 2)$ in two separate groups (traditional and digital). 
Table 2. Comparing means of each variable at T0, T1 and T2 for traditional group (\%).

\begin{tabular}{ccccccc}
\hline Variable & T0 $(\mathbf{n}=\mathbf{1 0})$ & T1 $(\mathbf{n}=\mathbf{1 0})$ & T2 $\mathbf{n}=\mathbf{1 0})$ & T0 vs. T1 & T1 vs. T2 & T0 vs. T2 \\
\hline & Mean \pm SD & Mean \pm SD & Mean \pm SD & $p$-Value & $p$-Value & $p$-Value \\
\hline POC TA & $77.8 \pm 10.28$ & $85.15 \pm 3.07$ & $86.1 \pm 4.1$ & $0.017^{*}$ & 0.203 & $0.005^{* *}$ \\
POC MM & $82.47 \pm 4.85$ & $84.34 \pm 4.9$ & $85.87 \pm 2.6$ & 0.285 & 0.285 & 0.139 \\
BAR & $78.89 \pm 13.2$ & $85.72 \pm 4.9$ & $88.92 \pm 2.8$ & 0.059 & 0.093 & $0.013^{*}$ \\
TORS & $86.84 \pm 4.10$ & $89.41 \pm 1.8$ & $90.19 \pm 1.86$ & 0.203 & 0.333 & 0.093 \\
IMP & $70.88 \pm 14.34$ & $108.58 \pm 36.11$ & $113.3 \pm 51.19$ & $0.007^{* *}$ & 0.799 & $0.022^{*}$ \\
ASIM & $2.7 \pm 12.23$ & $3.79 \pm 5.17$ & $1.82 \pm 7.39$ & 0.799 & 0.333 & 0.799 \\
TOT & $80.80 \pm 7.33$ & $86.10 \pm 2.6$ & $88.1 \pm 2.33$ & $0.008^{* *}$ & $0.007^{* *}$ & $0.005^{* *}$ \\
\hline \multicolumn{7}{c}{$p<0.05 ; * *<0.01 ; n=$ number of the sample. }
\end{tabular}

Table 3. Comparing means of each variable at T0, T1 and T2 for digital group (\%).

\begin{tabular}{ccccccc}
\hline Variable & T0 $(\mathbf{n}=\mathbf{1 2})$ & T1 $(\mathbf{n}=\mathbf{1 2})$ & T2 $(\mathbf{n}=\mathbf{1 2})$ & T0 vs. T1 & T1 vs. T2 & T0 vs. T2 \\
\hline & Mean \pm SD & Mean \pm SD & Mean \pm SD & $p$-Value & $p$-Value & $p$-Value \\
\hline POC TA & $76.84 \pm 18.21$ & $83.13 \pm 7.48$ & $84.99 \pm 5.20$ & 0.695 & 0.084 & 0.084 \\
POC MM & $80.72 \pm 8.28$ & $79.89 \pm 10.01$ & $85.26 \pm 6.33$ & 0.875 & $0.019^{*}$ & $0.012^{*}$ \\
BAR & $77.94 \pm 17.96$ & $86.48 \pm 8.12$ & $88.58 \pm 4.63$ & $0.019^{*}$ & $0.041^{*}$ & $0.005^{* *}$ \\
TORS & $85.81 \pm 5.47$ & $88.04 \pm 4.98$ & $90.71 \pm 1.92$ & 0.084 & $0.015^{*}$ & $0.002^{* *}$ \\
IMP & $102.59 \pm 38.88$ & $107.54 \pm 57.24$ & $111.21 \pm 54.77$ & 0.48 & 0.875 & 1 \\
ASIM & $4.15 \pm 18.15$ & $1.12 \pm 16.28$ & $0.78 \pm 40.85$ & 0.388 & 0.754 & 0.388 \\
TOT & $79.83 \pm 9.57$ & $84.92 \pm 6.26$ & $87.58 \pm 3.9$ & $0.004^{* *}$ & $0.007^{* *}$ & $0.003^{* *}$ \\
\hline
\end{tabular}

${ }^{*} p<0.05 ;{ }^{* *} p<0.01 ; \mathrm{n}=$ number of the sample.

For each of the seven parameters, the variation between the different times was analyzed.

Analysis of parameters at different times for the traditional group (Table 2) revealed a significant variation in POC TA and IMP at "T0 vs. T1" and "T0 vs. T2", BAR at "T0 vs. T2" and TOT at all three time comparisons.

In the digital group (Table 3), POC MM and TORS at "T1 vs. T2" and "T0 vs. T2", TORS at "T1 vs. T2" and "T0 vs. T2", BAR and TOT at all three time comparisons showed a significant difference.

Table 4 demonstrates the differences between the two groups (traditional and digital) at different time gaps. At $\Delta 1$ (T1-T0) only IMP showed a significant change and no other significant variation was observed between the two groups at $\Delta 2$ (T2-T1) and $\Delta 3$ (T2-T0). It can be substantiated from analysis results that traditional and digital methods generally have no significant differences.

Table 4. Differences between the two groups (traditional, digital) at different time gaps $(\Delta 1, \Delta 2, \Delta 3)$.

\begin{tabular}{|c|c|c|c|c|c|c|c|c|c|}
\hline \multirow[b]{2}{*}{ Variable } & \multicolumn{3}{|c|}{$\Delta 1=\mathrm{T} 1-\mathrm{T} 0$} & \multicolumn{3}{|c|}{$\Delta 2=\mathrm{T} 2-\mathrm{T} 1$} & \multicolumn{3}{|c|}{$\Delta 3=\mathrm{T} 2-\mathrm{T} 0$} \\
\hline & $\begin{array}{l}\text { Traditional } \\
(n=10)\end{array}$ & $\begin{array}{c}\text { CAD } \\
(n=12)\end{array}$ & & $\begin{array}{l}\text { Traditional } \\
\quad(n=10)\end{array}$ & $\begin{array}{c}\text { CAD } \\
(n=12)\end{array}$ & & $\begin{array}{l}\text { Traditional } \\
(\mathrm{n}=10)\end{array}$ & $\begin{array}{c}\text { CAD } \\
(n=12)\end{array}$ & \\
\hline POC TA & $7.33 \pm 9.59$ & $6.29 \pm 18.23$ & 0.129 & $0.96 \pm 2.51$ & $1.87 \pm 4.18$ & 0.644 & $8.29 \pm 10.68$ & $8.16 \pm 17.84$ & 0.51 \\
\hline POC MM & $1.87 \pm 5.04$ & $-0.84 \pm 7.02$ & 0.429 & $1.53 \pm 4.53$ & $5.37 \pm 7.10$ & 0.262 & $3.40 \pm 5.79$ & $4.53 \pm 6.23$ & 0.692 \\
\hline BAR & $6.84 \pm 13.47$ & $8.54 \pm 12$ & 0.692 & $3.19 \pm 4.63$ & $2.10 \pm 5.53$ & 0.921 & $10.03 \pm 13.14$ & $10.64 \pm 15.57$ & 1 \\
\hline ASIM & $1.09 \pm 13.55$ & $-3.03 \pm 14.58$ & 0.692 & $-1.97 \pm 5.24$ & $-0.34 \pm 14.76$ & 0.391 & $-0.88 \pm 13.27$ & $-3.36 \pm 16.06$ & 0.644 \\
\hline TOT & $5.30 \pm 7.89$ & $5.08 \pm 6.19$ & 0.868 & $2.00 \pm 1.41$ & $2.67 \pm 3.68$ & 0.838 & $7.3 \pm 7.63$ & $7.75 \pm 7.28$ & 0.895 \\
\hline
\end{tabular}

\section{Discussion}

This controlled prospective study compares the impact on masticatory muscle activity between two different techniques, while OVD was increased utilizing digital and traditional mockups. For determination of impact on masticatory muscle activity surface electromyography was employed, by using Teethan device, which consists of four wireless probes placed on the anterior temporal and 
masseter muscles to detect muscular activity during two clench tasks of $5 \mathrm{~s}$ each. This system makes it possible to determine the presence/absence of prevalences, torsions and imbalances through the analyses of collected data [17].

In both groups, at $\mathrm{T} 0$, the greater part of the parameters demonstrated values out of the normal range, while at $\mathrm{T} 2$, the majority of parameters in both groups changed significantly reaching the normal range showing a general improvement of muscular function and symmetry in both groups [12,24]. No significant differences were observed concerning $\Delta$ (delta) variation over time between digital and traditional techniques. At T2, in both groups, the EMG exam confirmed an absence of any predominance of left/right sides in the masticatory muscle activity (the parameters POC TA, POC $\mathrm{MM}$ and ASIM were in the normal range), the absence of any torque in the muscular function (the parameter TORS were in the normal range), and a normal pattern of muscular work (the parameters IMP and TOT were in the normal range).

Only slightly low values $(<90)$ were registered in both groups for the BAR parameter that indicates the distribution of forces between anterior and posterior segments of dental arches, suggesting the slight predominance of posterior forces and occlusal contacts that is typical of full arch prosthetic rehabilitation.

From the clinical point of view, the effect of OVD loss on masticatory efficiency demands our attention to avoid progressive damage, which may lead to create intensely destructive zones $[25,26]$.

Thus, restorative treatment can replace the loss of tooth structure and has been retrospectively observed to be able to obtain acceptable functional occlusal parameters (only functional complication, mostly a difficulty in speech were observed, which was solved in two weeks after rehabilitation) [27].

In the Sierpinska et al. study, 50 patients with advanced teeth wear who received prosthodontic treatment using conventional wax up method, underwent electromyographic analysis of the anterior temporal and masseter muscles [28].

Although those authors report a general improvement of masticatory function after treatment that agrees with the present study, in their study no assessment of the symmetric index between right and left muscles was provided, and no normalization was carried out by closing the mouth while cotton rolls are placed inside. Thus, their obtained results are not directly comparable with the ones from the present study.

In the present study, slightly different distributions between the two groups at T1 for the IMP were observed. In particular, at T1, an excessive value for the IMP parameter was registered in the traditional group indicating an excessive muscular work, significantly higher than the digital group. This difference disappeared at $\mathrm{T} 2$ when in both groups the IMP parameter reached a normal value, with no significant difference between the two groups, thus it does not seem to be important for achieving the general success of prosthetic rehabilitation.

At the authors' knowledge this is the first study concerned with the assessment of functional/occlusal symmetry during prosthetic rehabilitation, in particular in the mockup phase, utilizing electromyography. The present findings suggest that for ensuring the final restoration of a functional symmetry both traditional and digital methods can still be considered to be effective and applicable procedures, in terms of impact on masseter and anterior temporalis muscle activity.

The advantages of the digital mockup technique can be mentioned as follows; it provides easier phonetic testing as the prosthesis is divided into two sections, and aesthetic evaluation can be achieved without difficulty. The digital mockup represents identical features as the definitive prosthesis is fabricated by the traditional technique in the form and points of contact (contacts absent in the anterior part of dental arch, and present at the posterior part) as well as the guide paths (incisive and canine, or group) can be early established. The digital mockup also allows the duplication of the occlusal surface with the anatomy similar to the one fabricated by the traditional method, helping to obtain earlier correct values of occlusal loads distribution on the anterior and posterior sectors of the arch, with a normal level of muscular work. 
While in the traditional mockup, the material used (duralay resin) does not allow an exact duplication of the occlusal surface; moreover, the mockup structure is unique, with occlusal contacts both in the anterior and posterior sectors (multicontact horseshoe structure).

With the mockup obtained through the traditional technique, it seems very probable that high loads can be recorded from both anterior and posterior sectors. Furthermore, the duralay structure appears with a less detailed and flatter occlusal surface, more similar to the patient's worn dentition.

These differences could justify the fact that the data recorded at T1 in this study present slightly different distributions between the two groups. Perhaps, the mechanical properties and the occlusal surface of the digital (made from PMMA) versus traditional (made from duralay) mockup might be the reason to explain these minimal differences between the two groups at T1. This point was recently demonstrated in vitro by Rosentritt $\mathrm{M}$ et al. [29].

Although digital mock-up fabrication has some advantages over the traditional mock-up, no significant effect was shown on masticatory muscle function in subjects with no TMD using either of the two techniques (digital and traditional). Only a reduced short-term effect was observed in the group treated with the traditional mockup, but it could be important to analyze these effects also in a population of subjects affected by TMD.

The present study has some limitations, the main one concerns the reduced sample size that could be related with the absence of differences observed between the two groups, but it should be considered that it represents the first electromyographic study on this topic.

Because of the use of surface electromyography, it was not possible to evaluate the pterygoid muscle activity which could clarify the effect of appliances on the mandibular condyle's position. Further studies in this field are encouraged to confirm the absence of differences between digital and traditional mockup fabrication methods on masticatory muscle activity in larger samples and also in subjects affected by TMD.

\section{Conclusions}

Both digital and traditional methods in mockup fabrication appear to be effective in the improvement of the masticatory system muscle activity. Besides other possible positive/negative aspects of the two methods, they seem to give comparable results in terms of impact on masseter and anterior temporalis muscle activity and restoration of a symmetric muscular function.

Author Contributions: Conceptualization, S.T. and A.N.; methodology, S.T., A.N., F.C.; software, A.D.; validation, S.T., A.N., F.C.; formal analysis, S.T., A.N., A.D.; investigation, F.C.; data curation, S.T., A.N., F.C., V.S.; writing-original draft preparation, S.T., A.N., A.D., V.S.; writing-review and editing, S.T., A.D., F.B., A.N.; supervision, S.T., G.G., E.F.G.; project administration, S.T., G.G., E.F.G.; All authors have read and agreed to the published version of the manuscript.

Funding: This research received no external funding.

Acknowledgments: The authors want to acknowledge Roberto Broggi for his clinical support.

Conflicts of Interest: The authors declare no conflict of interest.

\section{Appendix A}

Table A1. Individual patient's demographic data and treatment time.

\begin{tabular}{ccccc}
\hline Patient & Group & Gender (F/M) & Age & T0-T2 Interval \\
\hline 1 & digital group & F & 31 & 4 months \\
2 & digital group & F & 36 & 5 months \\
3 & digital group & F & 38 & 4 months \\
4 & digital group & F & 48 & 5 months \\
5 & digital group & F & 44 & 4 months \\
6 & digital group & M & 46 & 5 months \\
7 & digital group & F & 43 & 4 months \\
\hline
\end{tabular}


Table A1. Cont.

\begin{tabular}{ccccc}
\hline Patient & Group & Gender (F/M) & Age & T0-T2 Interval \\
8 & digital group & $\mathrm{F}$ & 49 & 5 months \\
9 & digital group & $\mathrm{F}$ & 28 & 2 months \\
10 & digital group & $\mathrm{M}$ & 49 & 3 months \\
11 & digital group & $\mathrm{M}$ & 48 & 4 months \\
12 & digital group & $\mathrm{F}$ & 46 & 5 months \\
13 & traditional group & $\mathrm{F}$ & 42 & 3 months \\
14 & traditional group & $\mathrm{F}$ & 40 & 4 months \\
15 & traditional group & $\mathrm{F}$ & 24 & 4 months \\
16 & traditional group & $\mathrm{M}$ & 45 & 5 months \\
17 & traditional group & $\mathrm{F}$ & 65 & 5 months \\
18 & traditional group & $\mathrm{F}$ & 46 & 5 months \\
19 & traditional group & $\mathrm{M}$ & 47 & 4 months \\
20 & traditional group & $\mathrm{F}$ & 36 & 5 months \\
21 & traditional group & $\mathrm{F}$ & 35 & 4 months \\
22 & traditional group & $\mathrm{F}$ & 42 & 5 months \\
\hline
\end{tabular}

\section{References}

1. Green, J.I. Prevention and management of tooth wear: The role of dental technology. Prim. Dent. J. 2016, 5, 30-33. [PubMed]

2. Grütter, L.; Vailati, F. Full-mouth adhesive rehabilitation in case of severe dental erosion, a minimally invasive approach following the 3-step technique. Eur. J. Esthet Dent. 2013, 8, 358-375. [PubMed]

3. Koubi, S.; Gurel, G.; Margossian, P.; Massihi, R.; Tassery, H. A simplified approach for restoration of worn dentition using the full mock-up concept: Clinical case reports. Int. J. Periodontics Restor. Dent. 2018, 38, 189-197. [CrossRef]

4. Fabbri, G.; Cannistraro, G.; Pulcini, C.; Sorrentino, R. The full-mouth mock-up: A dynamic diagnostic approach (DDA) to test function and esthetics in complex rehabilitations with increased vertical dimension of occlusion. Int. J. Esthet. Dent. 2018, 13, 460-474. [PubMed]

5. Alhajj, M.N.; Khalifa, N.; Abduo, J.; Amran, A.G.; Ismail, I.A. Determination of occlusal vertical dimension for complete dentures patients: An updated review. J. Oral Rehabilit. 2017, 44, 896-907. [CrossRef]

6. Cattoni, F.; Mastrangelo, F.; Gherlone, E.F.; Gastaldi, G. A new total digital smile planning technique (3D-DSP) to fabricate CAD-CAM mockups for esthetic crowns and veneers. Int. J. Dent. 2016, 2016, 1-5. [CrossRef]

7. Libonati, A.; Nardi, R.; Gallusi, G.; Angotti, V.; Caruso, S.; Coniglione, F.; Marzo, G.; Mattei, A.; Tecco, S.; Paglia, L. Pain and anxiety associated with computer-controlled local anaesthesia: Systematic review and meta-analysis of cross-over studies. Eur. J. Paediatr Dent. 2018, 19, 324-332.

8. Nota, A.; Tecco, S.; Cioffi, C.; Beraldi, A.; Padulo, J.; Baldini, A. Occlusion time analysis in military pilots affected by bruxism. Sci. Rep. 2019, 9, 1-4. [CrossRef]

9. Nota, A.; Tecco, S.; Ehsani, S.; Padulo, J.; Baldini, A. Postural stability in subjects with temporomandibular disorders and healthy controls: A comparative assessment. J. Electromyogr. Kinesiol. 2017, 37, 21-24. [CrossRef]

10. López-Frías, F.J.; Castellanos-Cosano, L.; Martín-González, J.; Llamas-Carreras, J.M.; Segura-Egea, J.J. Clinical measurement of tooth wear: Tooth Wear Indices. J. Clin. Exp. Dent. 2012, 4, e48-e53. [CrossRef]

11. Jang, Y.S.; Nguyen, T.D.T.; Ko, Y.H.; Lee, D.W.; Baik, B.J.; Lee, M.H.; Bae, T.S. In vitro wear behavior between enamel cusp and three aesthetic restorative materials: Zirconia, porcelain, and composite resin. J. Adv. Prosthodont. 2019, 11,7-15. [CrossRef] [PubMed]

12. Tecco, S.; Mummolo, S.; Marchetti, E.; Teté, S.; Campanella, V.; Gatto, R. sEMG activity of masticatory, neck and trunk muscles during treatment of scoliosis with functional braces. A longitudinal controlled study. J. Electromyogr. Kinesiol. 2011, 21, 885-892. [CrossRef] [PubMed]

13. Tecco, S.; Baldini, A.; Mummolo, S.; Marchetti, E.; Giuca, M.R.; Marzo, G.; Gherlone, E.F. Frenulectomy of the tongue and the influence of rehabilitation exercises on the sEMG activity of masticatory muscles. J. Electromyogr. Kinesiol. 2015, 25, 619-628. [CrossRef] [PubMed] 
14. Moorrees, C.F. Natural head position-A revival. Am. J. Orthod. Dentofac. Orthop. 1994, 105, $512-513$. [CrossRef]

15. Silvestrini-Biavati, A.; Migliorati, M.; Demarziani, E.; Tecco, S.; Silvestrini-Biavati, P.; Polimeni, A.; Saccucci, M. Clinical association between teeth malocclusions, wrong posture and ocular convergence disorders: An epidemiological investigation on primary school children. BMC Pediatr. 2013, 13, 12. [CrossRef] [PubMed]

16. Ciuffolo, F.; Manzoli, L.; Ferritto, A.L.; Tecco, S.; D’Attilio, M.; Festa, F. Surface electromyographic response of the neck muscles to maximal voluntary clenching of the teeth. J. Oral Rehabilit. 2005, 32, 79-84. [CrossRef]

17. Ferrario, V.F.; Sforza, C.; Colombo, A.; Ciusa, V. An electromyographic investigation of masticatory muscles symmetry in normo-occlusion subjects. J. Oral Rehabilit. 2000, 27, 33-40. [CrossRef]

18. Ferrario, V.F.; Sforza, C. Coordinated electromyographic activity of the human masseter and temporalis anterior muscles during mastication. Eur. J. Oral Sci. 1996, 104, 511-517. [CrossRef]

19. Ferrario, V.F.; Sforza, C.; Serrao, G.; Colombo, A.; Schmitz, J.H. The effects of a single intercuspal interference on electromyographic characteristics of human masticatory muscles during maximal voluntary teeth clenching. Cranio 1999, 17, 184-188. [CrossRef]

20. Sforza, C.; Tartaglia, G.M.; Solimene, U.; Morgun, V.; Kaspranskiy, R.R.; Ferrario, V.F. Occlusion, sternocleidomastoid muscle activity, and body sway: A pilot study in male astronauts. Cranio 2006, 24, 43-49. [CrossRef]

21. Sforza, C.; Zanotti, G.; Mantovani, E.; Ferrario, V.F. Fatigue in the masseter and temporalis muscles at constant load. Cranio 2007, 25, 30-36. [CrossRef] [PubMed]

22. Botelho, A.L.; Gentil, F.H.U.; Sforza, C.; Da Silva, M.A.M.R. Standardization of the electromyographic signal through the maximum isometric voluntary contraction. Cranio 2011, 29, 23-31. [CrossRef] [PubMed]

23. Sforza, C.; Rosati, R.; De Menezes, M.; Musto, F.; Toma, M. EMG analysis of trapezius and masticatory muscles: Experimental protocol and data reproducibility. J. Oral Rehabilit. 2011, 38, 648-654. [CrossRef]

24. Mummolo, S.; Nota, A.; Tecco, S.; Caruso, S.; Marchetti, E.; Marzo, G.; Cutilli, T. Ultra-low-frequency transcutaneous electric nerve stimulation (ULF-TENS) in subjects with craniofacial pain: A retrospective study. Cranio 2018, 8, 1-6. [CrossRef] [PubMed]

25. Kumar, M.; Verma, R.; Bansal, M.; Singh, S.; Rehan, S.; Kumar, V. Simran to evaluate the severity, distribution of occlusal tooth wear and its correlation with bite force in young North Indian adults. Open Dent. J. 2018, 12, 735-741. [CrossRef]

26. Tecco, S.; Tetè, S.; D'Attilio, M.; Perillo, L.; Festa, F. Surface electromyographic patterns of masticatory, neck, and trunk muscles in temporomandibular joint dysfunction patients undergoing anterior repositioning splint therapy. Eur. J. Orthod. 2008, 30, 592-597. [CrossRef]

27. Fabbri, G.; Sorrentino, R.; Cannistraro, G. Increasing the vertical dimension of occlusion: A multicenter retrospective clinical comparative study on 100 patients with fixed tooth-supported, mixed, and implant-supported full-arch rehabilitations. Int. J. Periodontics Restor. Dent. 2018, 38, 323-335. [CrossRef]

28. Sierpinska, T.; Kuć, J.; Gołebiewska, M. Morphological and functional parameters in patients with tooth wear before and after treatment. Open Dent. J. 2013, 7, 55-61. [CrossRef]

29. Rosentritt, M.; Raab, P.; Hahnel, S.; Stöckle, M.; Preis, V. In-vitro performance of CAD/CAM-fabricated implant-supported temporary crowns. Clin. Oral Investig. 2017, 21, 2581-2587. [CrossRef]

(C) 2020 by the authors. Licensee MDPI, Basel, Switzerland. This article is an open access article distributed under the terms and conditions of the Creative Commons Attribution (CC BY) license (http://creativecommons.org/licenses/by/4.0/). 